\title{
MULTICRITERIA SELECTION OF THE OPTIMAL DESIGN OPTIONS OF TELECOMMUNICATION FACILITIES
}

\author{
Valeriy Bezruk, Daria Chebotareva, Yulia Skoryk \\ Kharkiv National University of Radio Electronics, Department of the Information and Network Engineering
}

Abstract. The peculiarities of the application of methods of multicriteria optimization in the choice of optimal design options of telecommunication facilities taking into account a set of quality indicators are considered. Examples of multicriteria analysis and the choice of optimal variants for various telecommunication facilities, in particular, the variants of radio network construction of a mobile communication system, the structure and methods of routing in multiservice networks, ad-hoc networks, sensor and actuator networks, as well as mobile communication technologies of the 4th generation are provided.

Keywords: telecommunication facilities, designing, multicriteria optimization, optimal design options

\section{WIELOKRYTERIALNY WYBÓR OPTYMALNYCH OPCJI PROJEKTOWYCH DLA TELEKOMUNIKACJI}

Streszczenie. Rozważono osobliwości zastosowania metod optymalizacji wielokryterialnej w wyborze optymalnych opcji projektowych urządzen telekomunikacyjnych z uwzględnieniem zestawu wskaźników jakości. Podane zostały przykłady analizy wielokryterialnej $i$ wyboru optymalnych wariantów dla różnych obiektów telekomunikacyjnych, w szczególności wariantów budowy sieci radiowej systemu komunikacji mobilnej, struktury i metod trasowania w sieciach wieloustugowych, sieciach ad-hoc, sieciach czujników i urzadzeń wykonawczych, a także technologie komunikacji mobilnej czwartej generacji.

Słowa kluczowe: urządzenia telekomunikacyjne, projektowanie, optymalizacja wielokryterialna, optymalne opcje projektowe

\section{Introduction}

Telecommunications facilities significantly affect the user service quality of infocommunication services. Therefore, there are requirements for the strict consideration of technical and economic requirements that are evaluated by the values of the relevant quality indicators, when choosing the best variant from a given set of feasible options of telecommunication facilities. This determines the necessity of using multicriteria optimization methods in choosing optimal design options for telecommunications facilities [1-6].

In this article, practical features of the application of multicriteria optimization methodology for solving various tasks of planning and designing of communication networks with consideration of the set of quality indicators are considered. Examples of multicriteria choice of optimal variants of communication networks in the tasks of nominal planning of cellular communication networks, selection of optimal variants of the structure of the data transmission network, choice of optimal routing in a multiservice communication network, selection of the preferred option of the routing protocol in ad-hoc networks and in the wireless sensor and actuator network, the choice of a prevailing telecommunication technology in mobile networks were provided [7].

\section{Methodology of multicriteria optimization for the selection of optimal design solutions}

In the work [7], a methodology of multicriteria optimization for the choice of optimal design solutions based on a set of quality indicators is presented. It includes the implementation of the following design procedures: the formation of a certain set of acceptable design solutions, evaluation of design options for a set of quality indicators and their representation in the criteria space of their assessments, setting of vector optimality criterion that takes into account a set of quality indicators, as well as the chose of design options optimal for the chosen optimality criterion. In the case of the usage of the unconditional advantage criterion (ADC), the optimal design variants correspond to Pareto-optimal estimates in the criterion space. When finding a subset of the Pareto-optimal design options worse design decisions are certainly excluded. The resulting Pareto-optimal design options are incomparable between themselves by ADC. In order to further narrow the Pareto subset and select a single design option for its further practical implementation, it is necessary to additionally introduce the conditional advantage criterion (CAC) using additional information from experts about the preference. There are a number of formalized methods for considering this information when constructing a formalized procedure that implements the selection of a single design option by CAC. In particular, it is a method of analyzing hierarchies, a lexographic method, a method of successive concessions, methods based on the utility theory and the theory of fuzzy sets.

\section{Multicriteria optimization at the stage of nominal cellular communication network planning}

Practical peculiarities of the application of multicriteria optimization methodology at the stage of nominal planning of cellular networks of mobile communication (CNC) were considered.

Finding the optimal design options for $\mathrm{CNC}$ with nominal CNC planning, considering the aggregate of quality indicators, includes the following stages:

- setting the initial set of network options that differ by data on the service area, the allocated frequency line, the number of users and others;

- selection of a set of permissible options taking into account restrictions on the structure and parameters of the network, as well as restrictions on the values of quality indicators;

- selection of a subset of Pareto-optimal network options using ADC;

- analysis of the obtained Pareto-optimal network options, evaluation of their multidimensional potential characteristics and multidimensional diagrams of the exchange of quality indicators:

- selection of a single network design variant from Paretooptimal subset using the specified CAC.

In the example, a set of permissible $\mathrm{CNC}$ options was formed, determined by different data on the planned number of subscribers in the network, size of the serviced territory, subscribers activity, allocated frequency line, cluster size, transmitter power of base stations (BS), allowable call blocking, percentage of the time 
of communication quality deterioration. As a result of the calculations, an initial (nominal) frequency-territorial plan has been developed and a subset of permissible options of CNC have been formed. An example of the nominal CNC planning was considered and it was possible to select the following quality indicators: $k_{1}$ - probability of error, $k_{2}$ - network capacity, $k_{3}$ - number of base stations in the network, $k_{4}$ - efficiency of radio frequency spectrum use, $k_{5}-$ probability of blocking, $k_{6}-$ coverage area. For each design version of the $\mathrm{CNC}$, estimates of the values of the specified quality indicators were found, their rationing to maximum values was carried out and brought to a comparative form. The finding of a subset of the optimal variants of CNC was carried out in the criteria space $\mathrm{V}$ of assessments of the vector of entered quality indicators $\vec{k}=\left(k_{1}, k_{2}, k_{3}, k_{4}, k_{5}, k_{6}\right)$.

An initial set of 100 options of construction of CNC was formed. In the criterion space of the corresponding vector estimates $\vec{k}$, a subset of optimal estimates for the binary relation of a non-strict preference $\geq$ in the space of estimates $V$, which is also called a subset of Pareto-optimal estimates $P(V)=o p t_{\geq} V$, was identified. The inclusion of vector estimates in this subset $\vec{k}^{0} \in P(V)$ was performed if and only if there were no other vector estimates $\vec{k}$ for which vector inequality would hold $\vec{k} \geq \vec{k}$.

Such a criterion for the choice of optimal solutions is called an unconditional advantage or Pareto criterion. The detected subset of Pareto-optimal estimates corresponds to the subset of Paretooptimal variants of SMS.

According to the given formalized selection procedure, in the considered example of the 100 design SMS options, 71 Paretooptimal CNC construction options were selected. At the same time, 29 certainly the worst by the Pareto criterion options for $\mathrm{CNC}$ construction were rejected.

For the obtained Pareto-optimal design options, the following properties are characteristic:

1) All variants of SMS, which do not belong to the Paretooptimal set are definitely worse.

2) All Pareto optimal versions of the SMS cannot be recognized as definitely worse or better than another version of the Pareto subset. This means that they are all not comparable to the Pareto criterion.

3) Each Pareto-optimal version of the SMS is responsible for the potentially possible value of each of the quality indicators $\vec{k}$, which can be achieved with fixed, but arbitrary values of other quality indicators. This is the property of the agreed multiplier optimum. The set of such optimal values of quality indicators is multidimensional potential characteristics of the system (MPC).

In order to choose from the found subset of Pareto-optimal variants a single design variant of $\mathrm{CNC}$, the CAC was used as a weighted sum of values of the selected quality indicators $k_{p}=\sum_{i=1}^{6} c_{i} k_{i}$. Provided minimum $k_{p}$ with $c_{i}=1 / 6$ from the obtained Pareto-optimal subset a unique variant of the construction of the CNC was selected, which is characterized by the following data: the number of subscribers in the network is 30,000 ; area of the served territory is $320 \mathrm{sq} \cdot \mathrm{km}$; subscriber activity -0.025 Earl; bandwidth $-4 \mathrm{MHz}$; admissible probability of call blocking -0.01 ; percentage of time of deterioration of communication quality - 0.07; allowable density service - $94 \mathrm{act} \cdot \mathrm{sb} / \mathrm{sq} \cdot \mathrm{km}$; cluster size -7 ; the number of base stations in the network - 133; number of subscribers, serviced by one BS - 226; the efficiency of usage of the radio frequency spectrum - $1.614 \cdot 10^{-4} \mathrm{act} \cdot \mathrm{sb} / \mathrm{Hz}$; telephone loading - 3.326 Earl; probability of error $-5.277 \cdot 10^{-7}$.

\section{The selection of optimal design options for data network, taking into account a set of quality indicators}

The peculiarities of the application of the methodology of optimization for the selection of optimal project version of the data network with packet switching, taking into account the set of quality indicators were considered. The quality indicators which are determined by the time of delivery and the possibility of packet loss in the framework of the datagram transmission of messages were defined. These quality indicators are interconnected and are antagonistic, that is, with the improvement of the value of one of the indicators, the other quality indicator deteriorates. Such a task of a data transmission network designing is relevant for practical applications that are critical to the timely delivery of messages, in particular, in video and voice messaging systems, banking terminal systems, alarm systems, troubleshooting systems in communication networks.

In the research, a mathematical model of a fully connected data transmission network topology was constructed. In the structure of mathematical model of the network, simulators of message sources, packaging messaging procedures in packages and their transmission via communication channels, routing and servicing procedures at switch nodes, error simulators in communication channels were introduced. The sources of messages with the Poisson law of distribution and different intensities of the flow of applications were modeled. Also, modeling of various delays in the transmission of packets associated with the final rate of signal propagation in communication channels, the fixed channel bandwidth, as well as the time that packets stay in the queue for transmission via the communication channels was carried out. Different variants of network operation were implemented that differed in the disciplines of packet data service in queues, routing methods for packet transmission, and the size of the transport connection window.

According to this problem thirty six variants of the network data transmission were given. As a result of simulation modeling, for each network option, estimates of quality indicators were found: average delivery time of packets $k_{1}=\bar{T}$ and average probability of loss of a message $k_{2}=\bar{P}$. In this case, the obtained admissible set of variants of the work of the network, which was presented in the criterion space of quality indicators estimates normalized to the maximum values. Here you can see a subset of Pareto-optimal network options by excluding definitely the worst options by the Pareto criterion.

Among the obtained Pareto-optimal variants of the network the only variant with the use of CAC was chosen - provided the minimum of the scalar function of value in the form of the resulting quality indicator $k_{p}=c_{1} k_{1}+c_{2} k_{2}$. For the case $c_{1}=0.4, c_{2}=0.6$ the only variant of the work of the network that was characterized was chosen: the discipline of service flow of applications - in a random manner by the method of routing uniform in accordance with the weight, the size of the "window" of transmission - equal to 8 . 


\section{Optimal routing in multiservice communication network, taking into account the set of quality indicators}

Multiservice communication network is a complex system with a set of elements and in order to provide high quality services of different types of traffic the actual task is optimal routing based on set of indicators. The peculiarities of applying of methodology of multicriteria optimization during the routing planning in such communication networks were considered.

The following multicriteria problem of routing was formulated. The set of acceptable solutions X (routes) in the final graph of the network $G=(V, E)$ was given, where $V$ - the set of nodes, $E$ - the set of connection lines. On a sat $X$ vector target function is given function $\bar{F}(x)=\left(F_{1}(x), \ldots, F_{v}(x), \ldots, F_{m}(x)\right)$ the components of which define the value of corresponding indicators of routs' quality $k_{v}$. The indicators of routs quality are connected and are antagonistic. The given task is the task of selection of the optimal routs options by the aggregate of quality indicators.

The solution of this problem is a subset of Pareto-optimal routing options, which corresponds to the agreed optimum of individual target functions $F_{1}(x), \ldots, F_{v}(x), \ldots, F_{m}(x)$ that determine the set of service quality indicators.

The choice of optimal routes taking into account a set of quality indicators means selecting a subset of Pareto-optimal routing options. The route option $\tilde{x} \in X$ is Pareto-optimal,

if there is no other route $x^{*} \in X$ for which irregularities

$F_{v}\left(x^{*}\right) \leq F_{v}(\tilde{x}), v=1, \ldots, m$ are performed, and at least one of them is strict. When comparing the routes for this vector criterion, the benefits of the set of acceptable options exclude definitely worse route options and remain Pareto-optimal route variants among themselves. The subset of Pareto-optimal route options corresponds to the Pareto optimum of quality indicators, that is, the minimum possible value of one of the quality indicators at a possible change in the values of another quality indicator.

The found Pareto-optimal route variants are incomparable from the point of view of the ADC - the Pareto criterion. The resulting subset of Pareto-optimal route options can be used to organize multi-route routing, in particular, in MPLS technology. This approach allows to implement load balancing and traffic control and provides a given quality of service for a set of quality indicators.

\section{The choice of the prevailing option for routing protocol in ad-hoc network based on hierarchy analysis method}

Hierarchy analysis method (HAM) is based on obtaining and formalized processing of information from experts in the form of matrices of pairwise comparisons of the importance of quality indicators, as well as design options with respect to each quality indicator $\left[a_{i j}\right]$. From a mathematical point of view, the processing of matrices of pairwise comparisons is reduced to the calculation of the principal eigenvectors of the matrix, which, after a certain rationing, becomes the vector of priorities of the elements of comparisons at a certain hierarchy level. Calculation of the estimates of the components of the main eigenvector of the matrix of pairwise comparisons is determined by a ratio

$$
V_{j}=\sqrt[n]{a_{i j}}, i=\overline{1, n},
$$

and assessments of the vector components of the priorities of quality indicators are determined by the ratio

$$
P_{j}=\frac{V_{n}}{\sum_{j=1}^{n} V_{n}}, j=\overline{1, n} .
$$

The obtained components of the priority vectors are used to calculate the components of the vector of global priorities according to the ratio

$$
C_{j}=\sum_{i=1}^{N} P_{i} P_{i j}, j=\overline{1, N},
$$

where $P_{i j}$ - the calculated priority vectors of the design options with respect to each quality indicator.

The number of the corresponding maximum components of the obtained vector of global priorities of the design variants in relation to each quality indicator $C_{j}$ corresponds to the prevailing design variant.

The features of the HAM application were considered for the selection of a single prevailing option for routing protocol in ad-hoc networks, taking into account the set of quality indicators [4]. A set of routing protocols included the following protocols: DSDV, OLSR, WRP, AODV, DSR. As protocols' quality indicators, the main characteristics of the protocols were selected, in particular $k_{1}$ - convergence time, $k_{2}$ - memory,

$k_{3}$ - management. These quality indicators are interconnected and competing. According to the hierarchy analysis method the matrix of paired comparisons of the importance of the quality parameters of routing protocols was constructed. Subsequently, paired comparisons of alternative variants of routing protocols with respect to selected quality indicators were performed and corresponding matrixes of pair comparisons were obtained. As a result of processing of received matrices, eigenvectors and vectors of priorities were calculated. Using these data, the components of the global priority vector were calculated. The prevailing option of the routing protocol in ad-hoc networks corresponds to the maximum value of the component of the global priority vector, taking into account the introduced quality indicators. This is the OLSR routing protocol, which is based on the Dijkstra's algorithm.

\section{The selection of the prevailing routing protocol in the wireless sensor and actuator network}

At present, wireless sensor and actuator networks (WSAN) have been actively developed, which are effectively used to solve applied tasks of distributed information collection on monitored parameters in monitoring networks. Such networks are homogeneous, self-organizing, peer, with cellular topology, whose nodes are capable of retransmission of information. Autonomous sources of the structural elements consumption of such networks in the form of batteries impose strict energy efficiency constraints on all routing protocols used in sensor networks. Therefore, for WSAN, routing tasks are important, in particular, the search of routes that are optimal in terms of energy efficiency and the search of routes that provide maximum network lifetime. The development of WSAN led to the emergence of a large number of routing protocols. Let's consider the features of the prevailing routing protocol selection in the WSAN by the hierarchy analysis method. 
A set of protocols was specified, including the following protocols: Sensor Protocols for Information via Negotiation (SPIN), Direcied Diffusion, Rumor Routing, Low Energy Adaptive Clustering Hierarchy (LEACH), Threshold Sensitive Energy Efficient Sensor Network Protocol (TEEN), PowerEfficient Gathering in Sensor Information Systems (PEGASIS, Self-OrganizingProtocol (SOP), Geographic Adaptive Fidelity (GAF), Geographicand Energy and Aware Routing (GEAR), Sequential Assignment Routing (SAR), Stateless Protocol for Real-Time Communication in Sensor Networks (SPEED).

To select a single prevailing routing protocol in WSAN, taking into account the aggregate of quality indicators, a hierarchy analysis method was used to obtain expert data on pair comparisons of the importance of quality indicators and routing protocols in WSAN in relation to these quality indicators. These data were processed and the values of components of the global priority vector $C_{j}$ were obtained. According to the hierarchy analysis method, the prevailing WSAN option is the GEAR routing protocol, which corresponds to the maximum component of the global priority vector.

\section{The selection of the prevailing technology in the 4th generation mobile network}

For comparative analysis, the following technologies of mobile communication were selected: HSPA (release 7 and separate amendments of the release 8), WiMAX (release 1.5) and LTE. At the same time, the following quality indicators for the specified mobile communication technologies were chosen: $k_{1}$ - spectral efficiency, $k_{2}$ - radius of action, $k_{3}$ - data transfer rate.

The quality indicators of these technologies are interconnected and competing, which determines the need to apply multicriteria optimization methods, in particular, the peculiarities of using the method of analysis of hierarchies for the choice of the prevailing option of mobile communication technology were considered. The matrix of paired comparisons of quality indicators was obtained, for which the components of the main eigenvector and the priority vector were calculated. Further, paired comparison of technologies in relation to selected quality indicators was conducted. After processing of the corresponding matrix of paired comparisons, the corresponding main eigenvectors and priorities vectors were obtained, which were used to calculate the components of the vector of global priorities $C_{j}$. The prevailing LTE technology with a data rate of $75 \mathrm{Mbit} / \mathrm{s}$, a spectral efficiency $-1.57 \mathrm{bits} / \mathrm{Hz} / \mathrm{s}$ and a radius of base stations $-5 \mathrm{~km}$ corresponds to the maximum value of the global priority vector components.

\section{Conclusions}

This article shows how to use a multicriteria approach when planning and designing optimal telecommunication facilities taking into account the totality of quality indicators. A number of examples that illustrate the practical features of applying the methods of multicriterion optimization when choosing the optimal design options for various types of communication networks were considered.

\section{References}

[1] Granat J., Wierzbicki A. P.: Multicriteria analysis in telecommunications Proceedings of the 37th Hawaii International Conference on System Sciences, 2004, 1-6.

[2] Mishra A. R.: Advanced Cellular Network Planning and Optimisation. 2G/2.5G/3G Evolution TO 4G. John Wiley \& Sons Ltd, London 2007.

[3] Grosan C., Abraham A., Hassainen A.: Designing resilient networks using multicriteria metaheuristics. Telecommunation System 40, 2009, 75-88.

[4] Saaty T.: Theory and Applications of the Analytic Network Process. Decision Making with Benefits, Opportunities, Costs and Risks. RWS Publications, Pittsburgh 2005.

[5] Lee H., Shi Y., Nazem S. M. et al.: Multicriteria hub decision making for rural area telecommunication networks. European Journal of Operational Research 133, 2001, 483-495.

[6] Carlos De Morais Cordeiro: Ad Hoc \& Sensor Net works: Theory and Applications. Agrawal World Scientific 1, 2006, 641.

[7] Bezruk V. M., Bukhanko A. N., Chebotareva D. V., Varich V. V.: Multicriterion optimization in telecommunication networks planning, designing and controlling. Telecommunications Networks. Current Status and Future Trends, Dr. Jesús Ortiz (Ed.), InTech, 2012, 251-274.

\section{Prof. Valeriy Bezruk}

e-mail: valeriy_bezruk@ukr.net

Doctor of Technical Sciences, Professor, Head of the "Information and Network Engineering Department" of the Kharkiv National University of Radio Electronics. In 1973 Valery Bezruk graduated from the Radio Engineering Department of the Kharkiv Institute of Radio Electronics on the specialty "Radio Engineering". In 2005 Valeriy Bezruk defended his doctoral dissertation

Area of scientific interests: statistical methods of processing and recognition of signals, mathematical modeling and multicriteria optimization of systems. Valery Bezruk has over 200 publications, including 5 monographs and 9 textbooks.

ORCID ID: 0000-0003-2349-7788

\begin{abstract}
Ph.D. Daria Chebotareva
e-mail: dariia.chebotarova@nure.ua

Candidate of technical sciences, Docent of the "Information and Network Engineering Department " of Kharkiv National University of Radio Electronics. In 2005 Daria Chebotareva graduated from the Telecommunications and Measuring Technology Department of Kharkiv National University of Radio Electronics on the speciality "Information Communication Networks". In 2012 Daria Chebotareva defended the thesis for the Candidate's Degree.

Area of scientific interests: planning and multicriteria optimization of communication networks. Daria Chebotareva is the author of over 50 publications, including 21 articles, 3 monographs and 1 textbook.
\end{abstract}

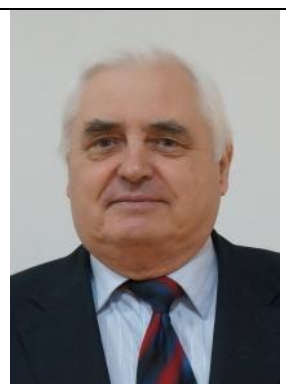

ORCID ID: 0000-0002-8442-8412

\section{Ph.D. Yulia Skoryk
e-mail: yuliia.skoryk@ nure.ua}

Candidate of technical sciences, Docent of the "Information and Network Engineering Department" of Kharkiv National University of Radio Electronics. In 2008 Yulia Skoryk graduated from the Telecommunications and Measuring Technology Department of Kharkiv National University of Radio Electronics on the speciality "Information Communication Networks". In 2014 Julia Skoryk defended the thesis for the Candidate's Degree. Area of scientific interests: multicriteria optimization of telecommunication facilities. Yulia Skoryk is the author of more than 30 publications, including 16 articles, 2 monographs.

ORCID ID: 0000-0003-1729-1003

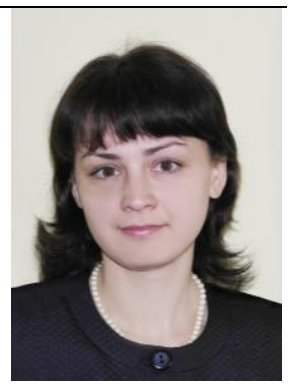

otrzymano/received: $1.10 .2018 \quad$ przyjęto do druku/accepted: 15.12 .2018 